\title{
Filantropía y asistencialismo. Fórmulas de legitimación de los programas de contratación en origen de temporeros agrícolas extranjeros en Cataluña
}

\author{
Olga Achón Rodríguez
}

\section{Resumen}

En el presente trabajo abordamos críticamente el papel que ha jugado la principal organización empresarial catalana, Unió de Pagesos (UP), como gestora de proyectos asistencialistas en Cataluña y de codesarrollo en Colombia, establecidos al alero de las contrataciones en origen de temporeros agrícolas. Desde el establecimiento de las primeras contrataciones colectivas de trabajadores en origen en Cataluña, UP ha desarrollado y perfeccionado un modelo de corte filantrópico basado en la asistencia social en destino y la generación de programas de codesarrollo en origen, que sirve al propósito de la legitimación de su sistema de suministro de mano de obra. Ha sido gracias a su fundación Agricultores Solidarios que este modelo filantrópico asistencialista se ha desarrollado tanto en lo que a los proyectos de formación y asistencia social se refiere, como en lo tocante a los cursos de formación de agentes de codesarrollo y a la implementación de los proyectos de codesarrollo. La realización del trabajo de campo nos proporciona material para la interpretación de estos programas asistencialistas, como proyectos de disciplina social útiles a la legitimación del sistema de reclutamiento e importación de mano de obra.

\section{Palabras Clave}

Codesarrollo; programas de trabajadores temporales extranjeros; enclave agrícola globalizado; filantropía; asistencialismo.

\section{TITLE}

Philanthropy and assistentialism. Formulas to legitimize temporary worker programs of foreign agricultural workers in Catalonia

\begin{abstract}
This paper studies the role played by the main Catalonian agricultural business organization - Unió de Pagesos- in the management of assistance based projects in Catalonia and codevelopment projects in Colombia, and set in the framework of temporary agricultural worker programs. Since the first import of workers to Catalonia, Unió de Pagesos has developed and attuned a model that seeks to legitimize a system of importation and supply of workers, which is based on relief-aid and co-development programs in the name of philanthropy. It is by way of the Farmers Solidarity foundation that the philanthropic model has been developed in three different areas: in training projects and social work, the training of codevelopment agents and the implementation of co-development projects. The fulfillment of the fieldwork provides us with material for an understanding of these assistance programs as social discipline projects, which are useful for the legitimization of the recruitment and importation of labour.
\end{abstract}

\section{KEYWORDS}

Codevelopment; Temporary Worker Programs; Globalized Agricultural Enclave; Philanthropy; Assistentialism. 


\section{ntroducción}

Desde 1998, y durante el tiempo en el que se extienden las campañas agrícolas en Cataluña, la organización empresarial agrícola Unió de Pagesos implementa un sistema particular de contratación de trabajadores en origen. Denominado aquí de reclutamiento, importación, movilización, concentración y suministro, tiene como finalidad la fijación de la mano de obra requerida por el sector agrícola, a través de la limitación de libertades de trabajo y circulación ${ }^{1}$.

A modo de estrategia legitimadora del sistema, desde la primera experiencia de contratación en origen se fueron elaborando anualmente diversos programas de carácter asistencial destinados a la "acogida y acompañamiento" de los trabajadores que fueron contratados mediante la vía de la Contratación Colectiva de Trabajadores en origen. Por otro lado, y en razón de tal función, se establecieron otros proyectos encaminados a la formación de los trabajadores en competencias lingüísticas, jurídicas y tecnológicas, así como a la cualificación de los trabajadores para el mejor desempeño de las tareas agrícolas para las que fueron contratados y para la prevención de los riesgos laborales. Sobre éstos programas profundizamos en páginas sucesivas ofreciendo mayor detalle sobre su gestión y desarrollo.

Fue principalmente en el interior de los alojamientos dispuestos para concentrar a los trabajadores que estos proyectos se ejecutaban - con mayor o menor éxito- por parte del personal encargado de la gestión de los mismos e inicialmente de forma más o menos improvisada. A medida que el sistema de reclutamiento y suministro de mano de obra extranjera iba consolidándose Unió de Pagesos agrupó a diversos profesionales, algunos de ellos formados en ciencias sociales y de la educación, con el objeto de crear una institución especializada en la gestión e implementación de proyectos asistenciales en destino y de codesarrollo en origen. Se trata de la Fundación Agricultores Solidarios establecida en el año 2001. La forma jurídica de fundación resolvía las demandas relacionadas con el objetivo de la legitimación del sistema.

A través de dicha Fundación, el quehacer filantrópico de Unió de Pagesos se realiza favoreciendo el propósito de la legitimación social, el que se expresaba eficazmente durante nuestro trabajo de campo a través de los cursos de formación, de acogida y de acompañamiento. Denominado por otros autores como "brazo filantrópico" ${ }^{2}$ de la organización patronal del campo catalán, con el tiempo sus funciones fueron ampliándose pasando a diversificarse entre aquéllas dedicadas a la recepción y custodia en los alojamientos, suministro a los empresarios y administración del ocio de los trabajadores; a otras centradas en la captación de lo que más tarde se acordó en denominar "agentes de codesarrollo". Ha sido a través de estos programas de codesarrollo que la Fundación ha prosperado en el contexto propio de las organizaciones dedicadas a la cooperación para el desarrollo, tomando posición en el área gracias, entre otros factores, a su vinculación con la Organización Internacional para las Migraciones y la Unión Europea.

\footnotetext{
1 Véase ACHÓN RODRÍGUEZ, Olga, Importando miseria. La alternativa a la provisión de mano de obra agrícola, Los libros de la Catarata, Madrid, 2011 y ACHÓN RODRÍGUEZ, Olga, "Contratación de temporeros por la Unió de Pagesos: un sistema sorprendente y censurable" en Revista Aranzadi Social, n 4, 2011, pp. 201-231.

2 Véase NEWLAND, Kathleen; AGUNIAS, Dovelyn Rannveig y TERRAZAS, Aaron, "Learning by doing. Experiences of circular migration" en Insight. Program on Migrants, Migration and Development. Migration Policy Institute, 2008, pp. 1-26, disponible en línea en: http://www.ime.gob.mx/investigaciones/2008/mig_learning_doing_ experiences_circular_migration.pdf [Consultado el 15 de diciembre de 2016].
} 
El presente artículo trata de mostrar el modo en que estos programas asistenciales y de codesarrollo se desarrollaron, o intentaron desarrollar, y la razón de sus propósitos. Igualmente intenta evidenciar la función legitimadora que atribuimos al sistema de reclutamiento y suministro establecido por Unió de Pagesos. Prestaremos especial atención asimismo al papel que juega la Fundación Agricultores Solidarios tanto en destino como en origen en tanto que desarrollador de la política filantrópico asistencial de Unió de Pagesos. Comprobar el alcance de los mismos sobre el conjunto de los trabajadores reclutados es objeto de este trabajo, en el que intentamos determinar en qué modo sirvieron y sirven al interés por legitimar el negocio de suministro de la organización empresarial.

Sobre el impacto de los proyectos de codesarrollo y su función legitimadora limitamos su examen a las informaciones recogidas en nuestro trabajo de campo, obtenidas a través de entrevistas de trabajadores en Cataluña, así como mediante la lectura de otros estudios empíricos. El recurso a nuestro trabajo de campo resulta de gran valor atendido el período en el que fue realizado (2003-2010), tiempo en el que se daba inicio a las primeras experiencias tanto de asistencia como de codesarrollo por parte de la Fundación Agricultores Solidarios. En atención a tales objetivos este trabajo se estructura en tres apartados, de los cuales el primero describe y analiza los programas asistenciales en destino; el segundo presenta y analiza los programas de codesarrollo en origen; para pasar en el tercer capítulo a exponer las conclusiones.

\section{Metodología de la investigación}

La primera aproximación al contexto de la investigación se produce gracias a la contratación de la autora como encargada de alojamiento para llevar a cabo tareas de gestión en Montblanc (Cataluña) durante la campaña de la vendimia en el año 2003. Durante el período en el que ésta se desarrollaba tuvo la oportunidad de observar desde una posición privilegiada lo que allí acontecía. En su interior se advertía la sutil dominación que se ejercía sobre los trabajadores, por lo que se dispuso a la observación atenta del modo en que se instauraban las relaciones entre los que ejercitaban el poder de la organización patronal y los trabajadores; es decir a través del método de observación participante.

Nació de esta primera experiencia la inclinación por comprender las razones y el modo en que tal ejercicio se llevaba a cabo. Las características del espacio que obligaba a la realización de actividades en comunión con el resto de los que allí estaban presentes, la sujeción de los alojados a un régimen común de vida reglamentado, la presencia de personal encargado con capacidad para sancionar las conductas no deseadas por la organización, condujeron a la autora a interpretar el modelo como emparentable con lo que Goffman había denominado institución total. Considerado desde esta perspectiva, y estimando su cercanía con aquel tipo de establecimientos o lugares, la finalidad de algunos de los cuales siguiendo a Goffman ${ }^{3}$, consiste en la protección de la comunidad contra quienes constituyen un peligro para ella o se erigen en instrumentos al servicio del control de la mano de obra, no pudo sino asimilarlo en cierta medida a establecimientos que, como las cárceles o los campos de trabajo, se establecen como medios para la privación de libertades.

\footnotetext{
3 Véase GOFFMAN, Erving, Internados. Ensayos sobre la situación social de los enfermos mentales, Amorrortu, Buenos Aires, 2001, pp. 18.
} 
El tema que la autora registraba se transformaría en el objeto de investigación de su tesis de doctorado, que se extendió desde el año 2004 hasta el 2010. Tomar contacto con personal de la organización patronal, especialmente del Servicio de Contratación de Trabajadores y de la Fundación Agricultores Solidarios, no resultó ser una tarea compleja pues ya había trabado conocimiento con personal de ambas instituciones durante el tiempo en el que la autora se desempeñó como encargada de alojamiento. Fue gracias a esta colaboración que se obtuvo valiosa información documental interna del servicio y de la fundación, así como contactos con personal encargado de alojamiento al que se pudo entrevistar. Asimismo, sirvieron de acompañantes en la ejecución de algunas de las visitas a diferentes alojamientos, en el transcurso de las cuales se realizaron entrevistas a trabajadores que allí se alojaban.

Durante la campaña agrícola de 2006, sin embargo, su preciada asistencia disminuyó en intensidad lo que se atribuye al ánimo reticente de Unió de Pagesos a que la investigación siguiese en desarrollo. Esta percepción vino a ser confirmada a medida que se encontraban resistencias a seguir indagando tanto sobre el sistema de contratación, como sobre el estado de los alojamientos. Ejemplo de éstas son la colocación de carteles prohibiendo la entrada a los alojamientos a personas ajenas a la organización patronal, así como la toma de fotografías de los mismos. Igualmente se advertía oposición a cualquier tipo de aproximación al espacio del alojamiento y al terreno documental, al descubrir en el manual titulado "Guía orientativa para solucionar problemas" que manejaban las encargadas la apreciación de la llegada de prensa u otros al alojamiento como un problema; o al encontrar como respuesta a preguntas sobre el sistema de contratación expresiones del tipo "no creas que vamos a darte toda la información".

Ante esta situación se decidió continuar con el trabajo de campo hasta el año 2010 (siendo menores las salidas a terreno durante los años 2009 y 2010), prescindiendo de la aprobación de Unió de Pagesos, razón por la cual la mayor cantidad de información obtenida por observación directa de la autora de las dinámicas disciplinarias, y más específicamente de la realización al interior de los establecimientos de los talleres de formación, de los proyectos de acogida y acompañamiento, de los cursos de agentes de codesarrollo, entre otros, se restringe hasta el año 2006 fundamentalmente. Desde entonces un acercamiento desde el exterior se planteó como el modo idóneo para proseguir su desarrollo. Necesario fue en ese momento reunirse con trabajadores en bares y cafeterías de los municipios donde trabajaban, así como rondar los alojamientos en los que residían. Una cadena de informantes fue, de este modo, configurándose a medida que unos trabajadores solicitaban a otros, generalmente compañeros de alojamiento, que ofrecieran su testimonio en las entrevistas. Los aspectos del desarrollo del sistema de suministro de mano de obra que fueron abordados en atención al cambio de posición de la autora - al exterior de los alojamientos- variaron, enfocándose en adelante en la realización de historias de vida y el estudio del impacto de la crisis económica desde el año 2007 sobre el modelo. De tal modo, lo abordado en este trabajo se sitúa en el momento de mayor reclutamiento de trabajadores desde la puesta en marcha del sistema, sirviendo así a la configuración de una suerte de historia dispuesta a la comprensión de las razones para la implantación de los programas filantrópicos de Unió de Pagesos, tanto en origen como en destino, es decir, su legitimación social y política.

La información que se pudo obtener en la realización del trabajo de campo a partir de 
ese momento varió, por lo tanto, sustancialmente de aquélla a la que se tuvo acceso mientras la autora trabajaba como encargada de alojamiento. El conocimiento de las dinámicas que en su interior se llevaban a cabo, los protocolos de suministro y tácticas disciplinarias que en él se observaron, fue entonces enriquecido por este trabajo "desde fuera" gracias a los testimonios de otros trabajadores y encargadas, que accedían a ser entrevistados a pesar de la reticencia de Unió de Pagesos a que se continuara con el trabajo. Fue de este modo cómo, más allá de lo sucedido entre los años 2003 y 2006, la autora pudo cerciorarse de que lo que allí ocurría era extensible al resto de alojamientos colectivos gestionados por la organización.

El interés por el estudio de este tipo de alojamientos, distintos de aquellos denominados por Unió de Pagesos como "particulares" -y que diferencia la autora por no contar con personal encargado ni albergar un número significativo de trabajadores-, se debe a la especial dinámica que se produce al interior de los mismos. La caracterizan la supervisión y control de los trabajadores, necesaria a la transformación de los sujetos prestos a ser suministrados. Es por ello que se realizaron visitas a este tipo de alojamientos colectivos, tanto de titularidad de empresas agroalimentarias como de entes locales, generalmente ayuntamientos que los cedían al conjunto de agricultores de su municipio que emplean trabajadores a través de Unió de Pagesos. De aquellos la mayor parte se concentraban, en el tiempo en que se realizaba la investigación, en la comarca del Segrià, seguida de l'Urgell y el Plà d'Urgell, por lo que fue en estas demarcaciones donde se realizó el trabajo de campo. Esta opción metodológica encuentra su fundamento en la mayor densidad de alojamientos colectivos en la comarca del Segrià como se aprecia en el mapa. ${ }^{4}$

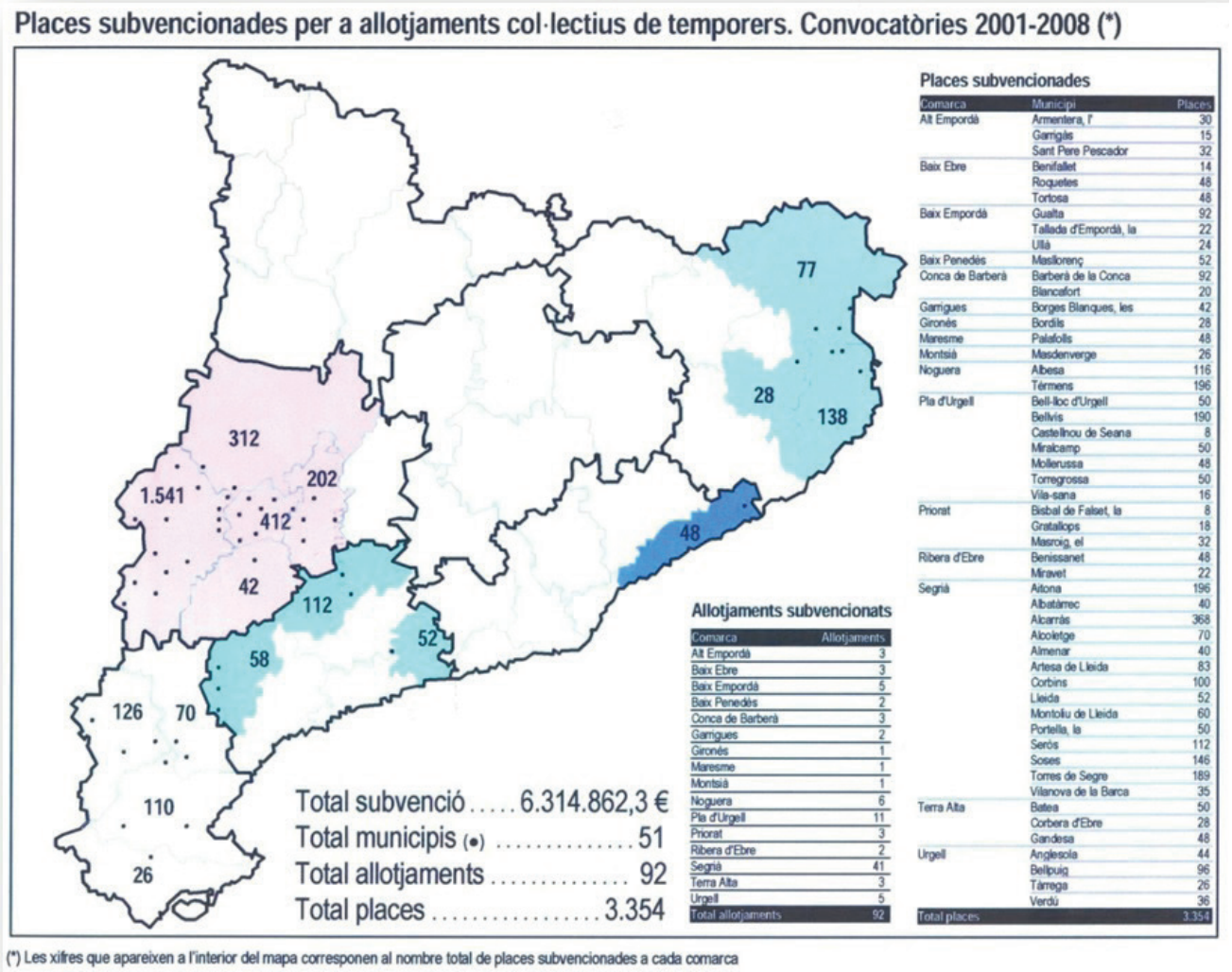

4 Mapa disponible en las bases de datos del buscador de información y documentación (CIDO) de la Diputació de Barcelona (DIBA), en el que se informa del número de plazas subvencionadas para el alojamiento de temporeros agrícolas contratados en origen en albergues colectivos. Disponible en https://www.diba.cat/c/document_ library/get_file?uuid=454aa796-d89c-4ff6-905d-0439e18ec848\&groupId=12812334 [consultado el 28 de julio de 2017. 
La información recogida en este mapa no refleja con exactitud la cantidad de alojamientos existentes en Catalunya, pues aquí sólo se expresan aquéllos con un cierto número de plazas subvencionadas. Tampoco hace distinción entre aquéllos de titularidad privada o pública. Ahora bien, se evidencia una mayor concentración de alojamientos colectivos en las comarcas visitadas, razón por la que fueron escogidas y que representan el marco territorial del estudio.

Así, en el Segrià, la autora se trasladó a Alcarràs, Alcoletge, Soses, Torres de Segre, Artesa de Lleida, Puigverd de Lleida, Corbins, Aitona y Serós, municipios en los que se visitó en varias ocasiones doce alojamientos colectivos, tanto de empresa como públicos, que representaban el $29 \%$ del total de una comarca que agrupaba para el año 2008 el 45\% del total de alojamientos subvencionados por el gobierno catalán. En el Plà d'Urgell se recorrieron en varias ocasiones seis alojamientos situados en Bell-Iloc, Bellvís, Mollerusa y Miralcamp, que representaban el 55\% del total de esa otra comarca para el mismo año, que a su vez reunía el $12 \%$ de los alojamientos catalanes subvencionados oficialmente. Para el caso de I'Urgell se visitaron tres alojamientos en los municipios de Bellpuig, La Fuliola y Verdú, que representaban el $60 \%$ del total de alojamientos de la misma y que constituían parte del $5 \%$ de los subvencionados de Catalunya para el año 2008. Adicionalmente se visitaron alojamientos en Montblanc, Les Pobles y Batea, pertenecientes a diversas comarcas, que no son tan representativas como las anteriores pues cuentan con menor número de alojamientos.

Estos establecimientos conformaron el terreno sobre el que se realizaron las incursiones necesarias a la elaboración de las diversas tipologías de alojamiento y su descripción. En ellos se tuvo la oportunidad de trabar contacto con las encargadas y los trabajadores que formarían parte del grupo de informantes, a los que se entrevistaba tanto al interior del alojamiento, como en su exterior. Sin embargo, las informaciones que auxiliaron en la tarea de la interpretación y el análisis - tanto al respecto de lo que en tales establecimientos sucedía, sobre lo que su implantación para el empresariado agrícola significaba, o como en lo que a su presentación en el espacio del municipio había representado- provinieron, además, de un sinfín de encuentros casuales. Agricultores, tanto contratantes del servicio de suministro de mano de obra de Unió de Pagesos, como otros cuya preferencia para hacerse con la fuerza de trabajo consistía en el empleo de trabajadores extranjeros en situación irregular o en la contratación de los servicios de gestorías y ETT's; vecinos de los municipios, en ocasiones involucrados en el establecimiento de la red de alojamientos debido, esencialmente, a los negocios de alquiler de inmuebles que establecieron con los ayuntamientos interesados en dotar de espacios para el albergue de trabajadores a los empresarios agrícolas. A su vez, extranjeros en busca de trabajo, entre otros, proporcionaron información a través de conversaciones informales en marcos tan variados como un descampado, un campo de perales, una panadería, una pequeña plaza de pueblo o las escaleras de una iglesia. Cuando estos encuentros se daban, el recurso al diario de campo se tornó imprescindible. En él se anotaban impresiones sobre cada acontecimiento, intuiciones sobre lo sucedido y pequeñas reflexiones que irían transformándose a medida que la investigación avanzaba. Las descripciones de los establecimientos serían igualmente consignadas en este preciado cuaderno llegando a constituir el diario de abordo de una singular expedición.

En cuanto a las entrevistas realizadas en profundidad, se efectuaron siguiendo un guion 
estructurado en orden a garantizar la discusión sobre temas relacionados principalmente, para el caso de los trabajadores, con la experiencia como interno, con el tipo de alojamientos en los que cada entrevistado residió, animando a su descripción y al relato de aspectos relacionados con el proceso de selección, reclutamiento y suministro, así como aquéllos relativos a la ejecución del trabajo al interior de empresas y campos, y sobre el desarrollo de cursos, talleres o el modo en que fueron transportados y recibidos en los alojamientos. Adicionalmente se interrogó a los trabajadores a propósito de la disminución del número de contrataciones en ocasión de la crisis económica, las estrategias a desarrollar en sus países de origen toda vez no volvieran a ser contratados, o sobre la posibilidad de no observar el compromiso de retorno y permanecer en el país por temor a no volver a ser reclutado. Respecto a los esquemas confeccionados para entrevistar al personal encargado, se centraban en temas vinculados esencialmente al trabajo cotidiano que ejecutaban relacionado con la gestión del grupo, la evaluación de actitudes de los trabajadores, la imposición de sanciones, las tareas relativas al suministro de mano de obra, así como su formación profesional y el tipo de alojamientos en los que desempeñó tales funciones.

Sobre la composición por sexo de los informantes, queremos realizar algunas puntualizaciones. La razón que explica la presencia exclusiva de hombres en nuestra investigación es que ésta se ha centrado, principalmente, en el análisis de los alojamientos colectivos de titularidad pública -denominados por Unió de Pagesos como "comunitarios"-, pues en ellos suele albergase a trabajadores dispuestos al suministro constante entre diversos empresarios agrícolas. La naturaleza de este tipo de alojamientos, que obliga a considerarlos como nódulos de suministro destinados al abastecimiento de mano de obra contratada en origen en favor de un amplio número de agricultores de un mismo municipio, explica la preferencia por su estudio. En ellos se concentra predominantemente mano de obra masculina, resultado de la convicción que los agricultores comparten de que el tipo de trabajo a desarrollar en sus explotaciones frutícolas requiere una gran fuerza física, tanto por su dureza como por las condiciones climatológicas bajo las que se ha de desarrollar. Así, mientras que en los establecimientos dispuestos en los alrededores de las plantas de envasado se encuentra en mayor porcentaje mano de obra femenina, en la categoría de alojamientos comunitarios en el campo la presencia masculina es predominante. La segmentación del mercado de trabajo agrícola por razones de género se encuentra por tanto puesta de manifiesto en nuestra muestra.

\section{Programas asistenciales en destino. Disciplinamiento obrero}

\subsection{Equipamiento colectivo e inmigración. Primera aproximación}

En el contexto del presente trabajo resulta de vital interés informar al lector del tipo de alojamiento en el que se llevó a cabo el trabajo de campo, esto es, un equipamiento de uso colectivo -0 comunitario ${ }^{5}$ en terminología de la organización-, especialmente establecido

\footnotetext{
5 Lo comunitario, en este contexto, hace referencia a la necesidad de control para el correcto suministro de los trabajadores por parte de Unió de Pagesos. Es debido a la ausencia de familias, al volumen de mano de obra que se concentra y por la condición de retorno al país de origen a que está sometida, que el alojamiento comunitario se implementa. En este sentido adquiere el término comunitario un cariz represivo, por lo que estaríamos de acuerdo en confirmar con Fourquet y Murard, que "estas nociones - 'social', 'colectivo' - encubren la dimensión de obligatoriedad que atraviesa a todo el concepto de equipamiento colectivo". Véase FOURQUET, François y MURARD, Lion, Los Equipamientos del Poder. Ciudades, Territorios y Equipamientos Colectivos, Editorial Gustavo Gili, Barcelona, 1978, p. 151.
} 
para la concentración y el suministro de los trabajadores contratados en origen. Se trata de un espacio cuyo principal objetivo es la generación de un movimiento ordenado de los individuos tanto en su interior (uso de instalaciones, régimen de visitas, normas de comportamiento, etc.), como en su exterior (asignación de temporeros a los distintos empresarios agrícolas y traslado de temporeros, reasignación o suspensión de trabajo con devolución al alojamiento a petición del empresario o debido a factores ambientales como la lluvia que impide la realización del trabajo, etc.). Consecuentemente, un espacio erigido con propósitos disciplinarios para el buen desempeño de la labor principal del personal encargado de tal equipamiento: el suministro de mano de obra.

Éste efectúa su quehacer atendiendo a diversas directrices que proporciona la organización empresarial, dispersas en varios documentos. De aquellas principales herramientas para el trabajo del encargado son las denominadas por Unió de Pagesos como "Normativa de alojamiento"6 y la "Guía para la formación de encargados". Fue mediante la inmersión en el terreno del alojamiento y la observación de lo que allí acontecía que llegamos a la interpretación de tales herramientas como mecanismos dirigidos al disciplinamiento obrero, no sólo en lo relativo a su cuerpo y su fuerza, sino a su movimiento.

De tal modo terminamos conceptulizando este equipamiento como un dispositivo de poder ${ }^{7}$, en terminología de Foucault, por cuanto se orienta al control social de los que allí se internan. La concentración, adecuada a la vigilancia de un sujeto doblemente peligroso por su cualidad de extranjero y trabajador, y la forma de gobierno autoritario que allí operaba, por la que los individuos quedan entregados a un proceso docilizador, son resultado de un sistema que pretende su explotación sistemática, su transformación en mano de obra rentable. El arte de su gobierno se basa en el establecimiento de relaciones que vinculan a encargados con sus superiores jerárquicos y con los trabajadores. Por medio de estas relaciones se ejercitaba el poder de la organización y se configuraba la institución del alojamiento que, mucho más allá de su instalación arquitectónica, resultó ser "todo comportamiento más o menos forzado, aprendido. Todo lo que en una sociedad funciona como sistema de coacción sin ser enunciado"8. El personal encargado por tanto puede definirse como un límite al ejercicio de la autonomía; un control impuesto para la verificación de las conductas que se permiten en el interior del alojamiento, amén de un programador y supervisor del movimiento regulado de la fuerza de trabajo en el territorio.

\footnotetext{
6 La transcripción de este particular código propuesto en el Proyecto de gestión de los alojamientos y seguimiento de los trabajadores, elaborado por la Unió de Pagesos en 2005 se encuentra en ACHÓN RODRÍGUEZ, Olga, Importando miseria... op.cit., pp. 132 y 133.

7 Por dispositivo de poder debe entenderse un conjunto variado de elementos que comprenden tanto discursos como instituciones, reglamentos y normativas, códigos administrativos, axiomas morales y/o filosóficos, e incluso estructuras arquitectónicas, y las relaciones que se establecen entre ellos conformando una red. Por tanto, lo que define nítidamente el dispositivo es la relación de los elementos constitutivos de una estructura reticular. El dispositivo manifiesta una urgencia por establecer una relación de poder y debe comprenderse como una condensación de elementos y relaciones, como una producción histórica. El concepto se ocupa en los estudios sobre control social y relaciones de poder tanto como concepto general como para designar y referir a instituciones sociales, discursos, procedimientos, etc. Véase FOUCAULT, Michel, La Verdad y las Formas Jurídicas, Gedisa, Barcelona, 1973 y FOUCAULT, Michel, Historia de la Locura en la Época Clásica, Fondo de Cultura Económica, Buenos Aires, 1990. En lo que a nuestra investigación refiere, el uso del concepto debe remitir al lector tanto al tipo de institución comunitaria y a su manifestación arquitectónica, como también a la normativa que rige el uso del espacio, la filosofía de la empresa, su misión asistencial y filantrópica declarada, e igualmente su propósito productivo.

8 Véase FOUCAULT, Michel, Saber y Verdad, Las Ediciones de La Piqueta, Madrid, 1991, pp. 93-132.
} 
La concepción del trabajador, por otro lado, como un sujeto de asistencia no responde sino a la necesidad de su encierro. Es la categoría "inmigrante" la que afecta su comprensión de la realidad del sistema y el alojamiento, tanto como del sujeto que se les presenta para ser reformado. Ésta es otra de las maniobras destinadas a desfigurar el auténtico cometido del sistema de suministro, del alojamiento y del quehacer de los encargados de los mismos: la concepción de los trabajadores contratados en origen como inmigrantes. Es decir, la asimilación de los trabajadores a inmigrantes actúa tanto como un motor de reproducción del sistema, como de producción de sujetos a los que reducir a vigilancia mientras se les somete a reforma.

Nuestro estudio sobre el estatuto jurídico ${ }^{9}$ de estos individuos dejaba claro sin embargo que de lo que se trataba era, nada más y nada menos, que, de trabajadores extranjeros, una entidad distinta de lo que en la España de la década de 1990 se comprendía como "inmigrante". Esta argucia conveniente tenía dos razones de ser, por un lado, la necesidad social de mostrarse frente a la sociedad civil como una organización empresarial preocupada por el bienestar y desarrollo social de los migrantes, por otro legitimar su programa de concentración y suministro de mano de obra en condiciones de explotación. En efecto, la voz "inmigrante" remite a una problemática ajena al sujeto que habita los alojamientos el cual, lejos de disfrutar las facultades que le son propias a un individuo que practica un movimiento autónomo -es decir, que es libre para desplazarse y buscar empleo-, es objeto de desplazamientos heterónomos previstos por Unió de Pagesos. La irrelevancia para ellos de los problemas a los que refiere el término "inmigrante", tales como la integración social, da cuenta de la debilidad de tal categoría para abordar el análisis de este fenómeno, pues el lugar segregado previsto para su residencia resulta ser un espacio liminal, algo parecido al no lugar, al menos tal y como Marc Augé ha popularizado ese concepto ${ }^{10}$. Su uso, no obstante, resulta oportuno al objeto de la legitimación de su aparición y progreso.

\subsection{Asistencia y disciplina. Estableciendo un proyecto filantrópico asistencial en los alojamientos comunitarios}

Encuadrados los trabajadores bajo esta categoría y movido el capital en su afán por edulcorar la realidad, propuso Unió de Pagesos la administración en el interior de los alojamientos de un programa asistencial entre cuyos objetivos manifiestos se encontraban "la mejora de su formación y el fomento de su autonomía"11. Los inicios de este programa se encuentran en el establecimiento de vínculos precarios con las entidades socioculturales de los primeros municipios con los que la organización empresarial acordó la gestión de los alojamientos cedidos por ellos. En efecto, el interés de los pueblos frutícolas de la región por entregar espacios de titularidad municipal en los que alojar a los trabajadores importados por Unió de Pagesos motivó la aparición de alojamientos comunitarios. Éstos, en algunos casos, habían estado ocupados inicialmente por trabajadores extranjeros residentes en el país -algunos en forma regular, otros muchos no-.

\footnotetext{
9 Véase ACHÓN RODRÍGUEZ, Olga, "Contratación de temporeros por la Unió de Pagesos..." op. cit., pp. 201-231.

10 Véase AUGÉ, Marc, Los "No Lugares". Espacios del Anonimato. Una Antropología de la Sobremodernidad, Gedisa, Barcelona, 2000.

${ }^{11}$ Queremos aquí hacer notar que estos conceptos son los que la organización patronal utilizaba en sus textos de formación para encargadas y otros textos dispersos a los que tuvimos acceso durante el trabajo de campo.
} 
Con la implantación progresiva del sistema de concentración y suministro de trabajadores la población en el interior de estos establecimientos fue mudando, hasta convertirse en lugar de concentración de la fuerza de trabajo únicamente contratada en origen. Un ejercicio de mejora de la imagen pública de los municipios podía presumirse, toda vez presentaban mediáticamente a este tipo de lugares como la solución a la desaparición progresiva de los conjuntos de chabolas, habitadas por extranjeros irregulares, existentes en la periferia de estos municipios. Su programa filantrópico comenzó a perfilarse entonces, su objetivo estaba claro: legitimar el sistema y dar publicidad a los proyectos de beneficencia de los municipios agrícolas.

Concertados tales intereses se dio inicio a las primeras iniciativas asistenciales consistentes en la organización de cursos en espacios municipales, tales como ludotecas, bibliotecas o mediatecas. Durante el transcurso del trabajo de campo pudimos ser testigos del modo en que estas actividades se organizaban y se desarrollaban en terreno. La publicidad de las mismas se realizaba al interior del alojamiento en los lapsos de tiempo destinados a reconstitución de la fuerza de trabajo, fundamentalmente a la hora de las comidas (en caso que los trabajadores tuvieran la oportunidad de regresar del campo al alojamiento para comer) y por la noche. El personal encargado comunicaba entonces, bien verbalmente o a través de carteles y volantes, la posibilidad que otorgaba el municipio de poder realizar cursos gratuitos o cuyo pago se consideraba simbólico. La publicidad de estos cursos, no obstante, no estaba exenta de la aplicación de cierta presión para integrar grupos cuyo número fuese el apropiado para la puesta en marcha de los mismos. Es el ideal del trabajador modelo, agradecido y sumiso ${ }^{12}$ el que la organización empresarial trataba de recrear aquí, por cuanto requería tanto la inscripción de los trabajadores en tales actividades, como la manifestación de cierta gratitud por su parte. Para lograrlo el personal encargado emprendía estrategias diversas para lograr su asentimiento, en ocasiones de persecución, cuyo resultado - a menudo improductivo- provocaba su decepción originando en consecuencia una actitud de reprensión.

Vienen a nuestra memoria situaciones en las que la investigadora en su rol de encargada de alojamiento tuvo que realizar la penosa operación de captación de trabajadores interesados en la realización de un curso de informática que debía llevarse a cabo en dependencias municipales en la localidad de Montblanc durante la temporada de la vendimia en el año 2003. Fue la indiferencia de los temporeros con respecto a esta oferta de formación la que imposibilitó su realización, pues apenas se sintieron atraídos por realizar el curso. La organización empresarial, en ocasión de esta propuesta de formación frustrada, hizo llegar al grupo de encargadas su molestia ante lo que ellos interpretaban como el desprecio de los trabajadores por la oferta. Ésta se expresaba mediante declaraciones del tipo "están desaprovechando oportunidades que no tienen en su país" o "no saben agradecer nuestra gestión, aunque va en su propio beneficio"13. Nuestro trabajo de campo atestigua cursos de informática y de catalán, principalmente. Los trabajadores, en atención a las entrevistas realizadas, declaraban no sentirse interesados por estas iniciativas. Antes, al contrario,

\footnotetext{
12 Véase SIERRA ÁLVAREZ, José, El Obrero Soñado. Ensayo sobre el Paternalismo Industrial (Asturias, 1860-1917), Siglo XXI, Madrid, 1990.

${ }^{13}$ Notas del diario de campo del año 2003.
} 
declaraban sentirse incómodos a causa de la presión ejercida por el personal encargado de los alojamientos.

El motivo principal por el que estas tensiones se suscitaban tiene relación con la necesidad de legitimación de un sistema de suministro de trabajadores dirigido a la explotación de su fuerza de trabajo. La publicidad del mismo dependía en gran medida de su presentación en sociedad como un modelo filantrópico que otorga trabajo y formación a extranjeros, liberando así a los municipios frutícolas de los inconvenientes que conlleva la contratación de extranjeros cuya situación jurídica era irregular. Es por ello, la inscripción voluntaria y masiva era la principal aspiración de la organización empresarial. El desarrollo de tales actividades no dependía exclusivamente de los recursos disponibles en los municipios.

En otras ocasiones y en ausencia de equipamiento municipal, Unió de Pagesos organizaba cursos y charlas de formación en el interior de los alojamientos. En ese caso se ponía en contacto con los profesionales adecuados para la realización de los cursos o charlas que se daban a los trabajadores para mejorar, en principio, su formación. El intervalo de tiempo en el que el trabajo de campo se extendió pudimos ser testigo de varias de estas iniciativas, entre las que se cuentan cursos breves de catalán y de prevención de riesgos laborales, así como charlas para la formación en materia de legislación de extranjería. El personal encargado de los alojamientos debía nuevamente instar a los trabajadores a que formasen parte de estos cursos y que destinasen parte de su tiempo libre a participar de las charlas.

Inscribirse en este tipo de actividades suponía en términos simbólicos una muestra de sometimiento al poder de la organización y al orden que ésta establece sobre el trabajo y la vida privada del trabajador. El alojamiento, por ser el lugar donde lo privado acontece, resulta ser el espacio idóneo al disciplinamiento de la conducta en el modo en que resulta beneficioso para el sistema de suministro. Se pretendía por tanto perfeccionarlo a través de la organización de los comportamientos individuales. Los trabajadores solían mostrar una actitud variable con respecto a este tipo de iniciativas, dependiendo del interlocutor con el que se relacionasen. Como pudimos comprobar, frente a Unió de Pagesos - fuesen técnicos de zona del servicio de contratación de trabajadores, o técnicos de la Fundació Pagesos Solidariscelebraban que éstas se llevasen a cabo, mas con la investigadora solían manifestar irritación y desagrado sobre todo por aquéllas que se realizaban en el alojamiento. Una suerte de invasión de su espacio privado era lo que con mayor vigor resentían: "Cuando venimos de trabajar sólo queremos descansar, conversar y... ya es bastante complicado todo acá, cocinar y hacer turnos y todo eso, encima tener que juntarse con todos los otros trabajadores para escuchar sobre cosas que a uno no le interesan"14.

En otros casos es el disgusto que la presión por participar generaba en los trabajadores pues les hacía mantener una actitud afectada y fingida de mansedumbre y benignidad: "Y pues tienes que mostrar que tienes interés y bueno, que eres una buena persona que no vas a meter en problemas a nadie, que vas a hacer caso de la normativa y te vas a portar bien con

${ }^{14}$ Extracto de entrevista realizada a Ernesto Suárez, trabajador colombiano, en el año 2005. 
el payés"15. De forma general podemos decir que todas las actividades formativas realizadas tanto dentro como fuera del alojamiento tenían escaso éxito de participación. No obstante, su intento de implementación no manifiesta sino la importancia que Unió de Pagesos les adjudicaba para legitimación de su sistema de suministro de temporeros.

Siguiendo con el análisis, no todo lo relacionado con el programa asistencial se reducía a cursos de formación. Parte importante del quehacer disciplinario de la organización se intentaba desarrollar mediante acciones de corte filantrópico que afectaban el ocio de los trabajadores. Estas iban desde la organización de campeonatos de futbol entre trabajadores residentes de alojamientos cercanos, a comidas de hermandad entre grupos de una misma nacionalidad o excursiones a lugares de interés turísticos. Si en este caso no solían los trabajadores oponer tanta resistencia a su realización, no podemos sino convenir que se trata de un modo de disciplina que remite a diversas estrategias históricas de control social de los trabajadores. En efecto, el ocio obrero es uno de los elementos a dominar, pues lo que a través de su gozo emerge no es sino el recuerdo de la libertad limitada. La organización del ocio y la ambicionada adhesión del grupo de trabajadores a la ideología de Unió de Pagesos, tanto como su participación voluntaria en el programa de formación, en fin, a todo su proyecto asistencial y su necesidad de éxito, no es sino la contrahaz de su sistema disciplinario. La organización de los cursos, la asistencia brindada, el "acompañamiento a los inmigrantes" que en su terminología brindan a los trabajadores importados, no resulta ser sino una forma sutil de disciplina de un tiempo que manifiestamente no es del trabajador.

La labor de la organización, por tanto, refiere a la necesidad de legitimar el sistema de importación y suministro de trabajadores y el modo en que éstos se concentran en los alojamientos. Sobre este "acompañamiento" quisiéramos, en este momento detenernos para comentar qué tipo de acciones se desarrollaban bajo su nombre. Formando parte del proyecto asistencialista en destino se estableció, desde los inicios del sistema de importación y suministro de trabajadores extranjeros en origen, un programa denominado de Acogida y Acompañamiento. La sola calificación de "acogida" remite al lector a cierta idea de protección y cuidado implícita en el concepto, útil a la necesidad de presentar a la institución prevista a la concentración de la mano de obra como un espacio destinado al cobijo, y en general al sistema de suministro como un conjunto de servicios orientados a la mejora de la calidad de vida de los trabajadores importados. La asimilación de los temporeros a la categoría de inmigrantes resulta conveniente a estos efectos, al comunicar tanto a encargados de alojamiento como a trabajadores - como a la sociedad más amplía en la que se insertan- una concepción eficaz de éstos como sujetos necesitados de ayuda y protección, y al sistema como un proyecto de cometido moral que se ofrece desinteresadamente.

Asimismo, el término "acompañamiento" apunta a una participación altruista en el, así concebido y difundido por Unió de Pagesos, "proyecto migratorio" de los temporeros. La realidad del alojamiento y el modo en que sirve a la circulación de la mano de obra por lo que denominamos corriente continua de fuerza de trabajo ${ }^{16}$, muestra que de lo que se trata

15 Extracto de entrevista realizada a Amador Ribera, trabajador colombiano, en el año 2005.

16 Véase ACHÓN RODRÍGUEZ, Olga, "Alojamientos para trabajadores agrícolas extranjeros contratados en origen y privación de libertades. El caso del sistema de alojamiento propuesto por el sindicato agrícola Unió de Pagesos en la comarca del Segriá (Lleida)" en FERNÁNDEZ AVILÉS, José Antonio y MORENO VIDA, María Nieves (dirs.), 
es de un programa de disciplina social del trabajador por el que se lo somete y vigila ${ }^{17}$. Las salidas a terreno y la experiencia de haber trabajado como encargada han resultado más que suficientes para atestiguar que lo que se denomina como "acogida" y "acompañamiento" no es sino un conjunto de maniobras integradas en la logística del sistema, indispensables para su puesta en funcionamiento. Estas comprenden acciones destinadas al transporte de los trabajadores desde el aeropuerto hasta el alojamiento, a su custodia -imprescindible para la supervisión del retorno obligatorio al que están sujetos los temporeros- y a su movilización ordenada y conveniente a la máxima exacción de plusvalía en atención al costo de su reclutamiento e importación.

Por otro lado, relacionado con el programa filantrópico que Unió de Pagesos trata de establecer en origen y por el que se generan proyectos de codesarrollo, se realizaban por parte del personal de la fundación Agricultores Solidarios aquello que desde la organización se acordó en Ilamar "Curso de agentes de codesarrollo". Finalizadas las campañas agrícolas, y una vez los encargados de alojamiento resolvían quienes eran de entre los trabajadores importados aquellos que encajaban con el perfil adecuado para desempeñar las funciones propias de los agentes de codesarrollo, se realizaban los citados cursos de codesarrollo en dependencias propias de Unió de Pagesos en Lleida. Tal resolución se enmarcaba en el contexto del programa disciplinario que se impartía en el interior de los alojamientos dispuesto para la eficiente distribución de los hombres. De tal forma, el juicio de los encargados de alojamiento venía a ser guiado por el modelo disciplinario que debía implementarse, específicamente debido a los criterios ${ }^{18}$ que intervienen en la producción de este sujeto/objeto que es el trabajador mismo. Por tanto, son los rasgos del "buen trabajador"19 los que los encargados de alojamiento debían tratar de descubrir en las personas de los trabajadores que manifestaban

Inmigración y Crisis Económica: Retos Políticos y de Ordenación Jurídica, Ed. Comares, Granada, 2011, pp. 533546.

17 Para el caso de los trabajadores mexicanos en el marco del Programa de Trabajadores Agrícolas Temporales (PTAT) en Quebec y en el suroeste de Ontario, Tanya Basok et. al. advierten de la creciente y constante presión por parte del patrón en la realización del trabajo y un aumento en el control de la vida privada del trabajador. Véase BASOK, Tanya; BÉLANGER, Danièle; CANDIZ, Guillermo y RIVAS, Eloy, "Espacios de "ilegalidad": el caso de trabajadores mexicanos en dos comunidades rurales de Canadá" en SÁNCHEZ GÓMEZ, Martha Judith y LARA FLORES, Sara María (coords.), Los Programas de Trabajadores Agrícolas Temporales. ¿Una Solución a los Retos de las Migraciones en la Globalización?, Universidad Nacional Autónoma de México e Instituto de Investigaciones Sociales, México, 2015, ps. 36-37. Sobre la confiscación de documentos para el control del desplazamiento de los trabajadores reclutados a través de las visas $\mathrm{H}-2 \mathrm{~A}$ para la agricultura estadounidense véase TRIGUEROS LEGARRETA, Paz "La contratación de trabajadores agrícolas con visas H-2A. Del Programa Bracero a la situación actual" en SÁNCHEZ GÓMEZ, Martha Judith y LARA FLORES, Sara María (coords.), Los Programas de Trabajadores Agrícolas Temporales..., op. cit.ps. 194-198. Similarmente Frédéric Décosse apunta a la situación de los trabajadores temporales marroquíes movilizados a través de los programas de trabajadores temporales gestionados por la Organización Internacional para las Migraciones, cuyo estatuto jurídico es sumamente precario. Véase DÉCOSSE, Frédéric, "Migración circular, (in)movilidad laboral y unfree labour. Una reflexión a partir del caso de los contratos OMI en Francia" en SÁNCHEZ GÓMEZ, Martha Judith y LARA FLORES, Sara María (coords.), Los Programas de Trabajadores Agrícolas Temporales..., op. cit. ps. 259-283.

${ }^{18}$ Criterios que subyacen en la documentación interna de Unió de Pagesos, a saber: memorias de campañas, guías para dirigir la actividad de la encargada en el interior de los alojamientos, normativas, etc. En todos estos documentos aflora la concepción del sujeto importado como un individuo problemático al que domar por el bien del sistema de reclutamiento, importación, concentración y suministro de trabajadores.

${ }^{19}$ Sobre el problema de las prácticas de reclutamiento de trabajadores guatemaltecos para la agricultura canadiense, llevadas a cabo por agencias privadas de reclutamiento, y su concepción del "buen trabajador", véase el trabajo de Gwendolyn Muir. La clasificación de "confiables" y "trabajadores" que estas agencias realizan de los trabajadores se comprende aquí como un modo de dominar y modelar trabajadores, y controlar la movilización de los contingentes de mano de obra. MUIR, Gwendolyn, "Descifrar los espacios de exclusión. El control de la migración y el reclutamiento de trabajadores guatemaltecos en Canadá a través del programa de trabajadores temporales extranjeros" en SÁNCHEZ GÓMEZ, Martha Judith y LARA FLORES, Sara María (coords.), Los programas de trabajadores agrícolas temporales... op.cit., pp. 57-80. 
tener intención de formar parte de los programas de codesarrollo. Según nuestra experiencia, reunida tanto a través de la realización de nuestro trabajo de campo como por el hecho de haber trabajado como encargada de alojamiento, los trabajadores en general no solían manifestar interés alguno por estos proyectos. Llamaba nuestra atención cómo los encargados se sentían compelidos a la exploración y búsqueda de interesados, tal como ocurría en el caso de la infructuosa incorporación de trabajadores voluntarios en cursos de formación ofertados por la fundación.

\section{Programas de codesarrollo en origen. El caso colombiano}

Interpretar el papel que desarrollaron los primeros proyectos de codesarrollo gestionados por la Fundación Agricultores Solidarios en relación a las necesidades de legitimación del sistema de reclutamiento de temporeros de Unió de Pagesos es también objeto de este artículo. Como ya mencionamos en otra ocasión ${ }^{20}$, la corriente de trabajadores colombianos que se instaura con la puesta en marcha del sistema de reclutamiento y posterior suministro de trabajadores ha precisado desde sus orígenes de un mecanismo que le sirva a la legitimación social del mismo.

Un argumento fundamental se esgrimía desde la organización con el establecimiento de los primeros programas de codesarrollo, como pudimos advertir durante la realización de nuestro trabajo de campo. Refería éste a la necesidad de concretar una red estable y duradera entre instituciones, en origen y en destino, para garantizar el igual recibo de beneficios tanto para el país emisor de trabajadores como el receptor. Éste revelaba, por un lado, en qué medida era consciente Unió de Pagesos sobre las ventajas que le suponía poder reclutar trabajadores en origen, relativas fundamentalmente a la posibilidad de establecimiento de su particular monopolio de servicios dedicado al suministro de fuerza de trabajo. Esto es, un sistema de fijación de mano de obra reclutada fuera del mercado de trabajo que se transformaría en objeto de sucesivos contratos de servicios entre la organización y los empresarios agrícolas demandantes de mano de obra.

"Para los agricultores el hecho que puedan contratar temporeros a través de nosotros es un gran qué. Primero las inspecciones, que luego el trabajador tanto te deja tirado en medio de la campaña. No es posible garantizar el éxito de la campaña sin trabajadores estables. Tirar de la contratación en origen ha sido una gran ventaja para los agricultores. ¿Cómo no íbamos a echarles un cable? Cuando vienen trabajadores que tienen una problemática equis, y nos la expresa, a mí me gustaría o tengo esta inquietud en mi país. ¿Cómo no ayudarles? iAh! iVale! ¿Qué podemos hacer? Nos inventamos algo. [...] Hasta que nos planteamos establecer algo como más sistematizado, y a partir de aquí comenzamos a trabajar lo de los agentes de codesarrollo."21

${ }^{20}$ Véase ACHÓN RODRÍGUEZ, Olga, "Colombianos para la fruticultura leridana. Análisis crítico de los protocolos de reclutamiento de temporeros" en SÁNCHEZ GÓMEZ, Martha Judith y LARA FLORES, Sara María (coords.), Los programas de trabajadores agrícolas temporales... op.cit., pp. 285-318.

${ }^{21}$ Extracto de entrevista a un técnico Servicio de Contratación de Temporeros realizada en el año 2005. En sucesivas entrevistas con este informante supimos de la puesta en marcha de lo que se ha venido a considerar como el primer ejemplo de proyecto de codesarrollo UP. Se trató de un proyecto de reforma y recuperación de la Capilla de Siecha: "La primera historia es que nos llegan de una comunidad en Colombia y nos dicen: tenemos una ermita que se nos ha caído o el tejado pero no tenemos dinero, ¿qué podríamos hacer algo? iVale! iPues hacemos una rifa! Hicimos una rifa y sacamos 300 euros, y con los trescientos euros arreglaron el tejado y pintaron e hicieron virguerías con aquella iglesia". Lo mismo ha venido a ser también consignado por Núria 
Las ventajas las advertían igualmente los municipios frutícolas que precisaban mano de obra en condiciones de sujeción y legalidad adecuadas a la finalización exitosa de las campañas agrícolas. Erradicar el chabolismo y las situaciones de explotación extrema, consignada por los medios de comunicación y la academia española se convirtió en una aspiración que podría lograrse a través del sistema establecido por Unió de Pagesos. El arribo de la contratación en origen sirvió así a la sustitución del vagabundo extranjero en busca de trabajo por el temporero movilizado, a la parcial erradicación de los campamentos de trabajadores pobres extranjeros y a la expansión de la red de alojamientos prevista a la concentración de la fuerza de trabajo contratada en origen.

Sin duda, aquello que resultó atractivo del modelo de contratación en origen, implementado por la organización patronal a través de su sistema, fue la capacidad de vincular la regulación de flujos y la ayuda para el desarrollo local en los países de origen ${ }^{22}$. El retorno del trabajador a su país exigido por la normativa española en materia de extranjería significó para Unió de Pagesos la ocasión ideal para la implementación de acciones de ayuda al desarrollo ${ }^{23}$. Éstas le proporcionaron la legitimación suficiente, ante la opinión pública, para el desarrollo de su sistema.

Tal interpretación de los beneficios obtenidos por cada una de las partes que entran en relación - trabajadores individualmente considerados, país de origen y país de destinoconstituyó el cimiento de las acciones previstas a la legitimación, ya no sólo del sistema sino en general del modelo de contratación en origen. Una lectura conveniente a los estados y organizaciones internacionales implicadas en el establecimiento y desarrollo de los programas, beneficioso para la economía de los municipios agrícolas, y rentable para las organizaciones que estos gestionan, sirvió de impulso para la normativización del modelo. Tal y como se ha venido reflejando en multitud de artículos académicos sobre lo que a nuestro parecer erróneamente se ha convenido en denominar "migración circular"24, esta interpretación en

Morelló, que caracteriza a este proyecto como parte de la mitología fundacional del codesarrollo implementado por Unió de Pagesos en Colombia. Véase MORELLÓ, Núria, Entre la Oportunidad y el Deseo. Contratación en Origen, Codesarrollo y Grupos Domésticos Transnacionales en el Mundo Rural. El Caso Catalunya-Colombia, Tesis inédita, 2016, p. 92.

${ }^{22}$ Frédéric Décosse apunta a lo mismo: el control migratorio y la regulación del reclutamiento y traslado de mano de obra. Este se logra a través de la movilidad internacional, disciplinada y la inmovilidad en el mercado laboral del país receptor. En efecto, en el caso francés esto se logra, como en el caso catalán a través de la obligación de retornar al país una vez terminado el trabajo para el que fue reclutado. Véase DÉCOSSE, Frédéric, "Migración circular, (in)movilidad laboral y unfree labour. Una reflexión a partir del caso de los contratos OMI en Francia" en SÁNCHEZ GÓMEZ, Martha Judith y LARA FLORES, Sara María (coords.), Los Programas de Trabajadores Agrícolas Temporales... op.cit. pp. 260. Nuestro análisis, en todo caso, del sistema de importación y suministro de trabajadores operado por Unió de Pagesos desmiente la existencia de un mercado de trabajo, por el contrario lo que se advierte es la existencia de un mercado de servicios en el que el trabajador actúa como un objeto de contratos establecidos entre la organización patronal y los empresarios agrícolas.

${ }^{23}$ Como bien apunta Morelló, "el programa constituye un incentivo para favorecer el retorno e incidir en las comunidades de origen". Véase MORELLÓ, Núria, Entre la Oportunidad y el Deseo..., op.cit., p. 91. Se debe fundamentalmente a este aspecto de la obligatoriedad de retornar al país de origen una vez vencido el tiempo de la visa, que no nos parece adecuado denominar al conjunto de acciones que desarrolla la Fundació Pagesos Solidaris como codesarrollo. No se trata simplemente de interpretar o no el resultado de las acciones que implementan como codesarrollo, sino de cuestionar la pertinencia del empleo de estos trabajadores en beneficio de la legitimación del sistema y de la organización que lo implementa.

${ }^{24}$ Ya profundizamos en este texto las razones que nos obligan a considerar a este sujeto no como un inmigrante sino como un trabajador cosificado. En primer lugar el trabajador no organiza autónomamente su movilización, la que adjetivamos en terminología de Jean Paul De Gaudemar como heterónoma al venir ésta dirigida por la organización patronal, y en segundo por su mutación de sujeto de derecho a objeto de sucesivos contratos de servicios entre Unió de Pagesos y los empresarios agrícolas. Véase DE GAUDEMAR, Jean Paul, La Movilización 
términos de beneficio calificado de "triple ganador" 25 no es sino una argucia discursiva eficiente para la legitimación de un modelo de control de flujos migratorios basado en la incorporación controlada de temporeros en situación de cosificación.

Por otro lado, los beneficios bajo esta visión utilitarista de los proyectos de codesarrollo se interpretaban, entonces como ahora, en clave de oportunidad para el establecimiento de relaciones de dependencia. La consideración del trabajo como un don sirve a estos efectos pues es gracias a esta donación que las comunidades de origen pueden recibir dinero en forma de remesas, las que no constituyen sino un modo de generar vínculos de subordinación entre la organización que ofrece trabajo y las comunidades que reciben los envíos de dinero. Es su consideración de mecanismos convenientes al desarrollo comunitario lo que posibilita una interpretación positiva de los programas de importación de temporeros que convienen a empresarios, organizaciones patronales, fundaciones, municipios productores y agencias internacionales. La percepción positiva de las remesas queda de tal modo expuesta y sirve a efectos de legitimar un sistema que no se nutre de migrantes, sino de unfree labor, siguiendo con la terminología de Décosse ${ }^{26}$.

Cabe preguntarse, teniendo en cuenta esta apreciación, si lo que se realiza en ocasión de la importación de trabajadores mediante este sistema es o no codesarrollo. A nuestro parecer tenemos ante nosotros un controvertido proyecto de, supuestamente codesarrollo, implementado por trabajadores que se ven forzados a retornar al país de origen bajo amenaza de ver suspendida su situación de legalidad en España y, en último caso, de expulsión en caso de abandonar el trabajo y, consecuentemente, el alojamiento o no regresar a Colombia. Ahora bien, remitiéndonos al concepto tal y como vino a ser interpretado por Sami Naïr, no parece ser adecuada la denominación de la actividad desarrollada por la Fundación Agricultores

General, La Piqueta, Madrid, 1981 y ACHÓN RODRÍGUEZ, Olga, "Contratación de temporeros por la Unió de Pagesos... op.cit. p. 212. Lejos de poder dirigirnos a este sujeto como un inmigrante no podemos sino denominarlos en términos de Yann Moulier-Boutang como trabajo asalariado embridado. Véase MOULIER-BOUTANG, Yann, De la Esclavitud al Trabajo Asalariado. Economía Histórica del Trabajo Asalariado Embridado, Akal, Madrid, 2006. En consecuencia consideramos el concepto de "migración circular" inadecuado para expresar la movilización de la que son objeto estos trabajadores. Otros argumentos relativos a la malformación del concepto "circular migration" elaborado por las ciencias sociales, con el que se caracteriza el desplazamiento autónomo de personas en contextos de baja o nula restricción de los flujos migratorios y en el que las fronteras se muestran porosas, es posible establecer en orden a refutar su uso para el caso de la movilización en comento.

25 Véase MARTIN, Philip, Managing Labor Migration: Temporary Worker Programs for the 21st Century, Internacional Institute for Labour Studies/OIT, Ginebra, 2003; RUHS, Martin, Temporary Foreign Workers Programs: Policies, Adverse Consequences and the Need to Make Them Work, CCIS/University of California, San Diego, Documento de trabajo n6/2002; ABELLA, Manolo, Policies and Best Practices for Management of Temporary Migration, Ponencia presentada en el International Symposium on International Migration and Development, Secretaría de las Naciones Unidas, Turín, 2006; MATA-CODESAL, Diana, Circular Codevelopement. Codevelopement for Temporary Migration Programs, 2007; ZAPATA-BARRERO, Ricard; FAÚNDEZ, Rocío. y SÁNCHEZ-MONTIJANO, Elena, Migración Laboral, Temporal y Circular (MLTC) de trabajadores entre Colombia y España. Un modelo a consolidar y replicar, 2009, https://www.academia.edu/996207/Migraci\%C3\%B3n_Laboral_Temporal_y_ Circular_MLTC_de_trabajadores_entre_Colombia_y_Espa\%C3\%B1a._Un_modelo_a_consolidar_Un_modelo_a_ consolidar_Un_modelo_a__ [Consultado el 20 de octubre de 2016]; MILLÁN JALDÓN, Juan Antonio, "Modelo Cartaya de Migración Circular: su definición conceptual y estratégica. Fórmula de codesarrollo idónea para fomentar flujos migratorios legales, complementar el control de frontera y la lucha contra el tráfico ilegal de personas y la migración ilegal" en GORDO MÁRQUEZ, Mercedes y FELICIDADES GARCÍA, Jesus (eds), Explorando los Contratos en Origen en los Campos Españoles, Universidad de Huelva, Huelva, 2009, pp. 147-154; y LÓPEZSALA, Ana y GODENAU, Dirk, "En torno a la circularidad migratoria: aproximaciones conceptuales, dimensiones teóricas y práctica política" en Migraciones, 38, 2015.

${ }^{26}$ Véase DÉCOSSE, Frédéric, "Migración circular, (in)movilidad laboral y unfree labour. Una reflexión a partir del caso de los contratos OMI en Francia" en SÁNCHEZ GÓMEZ, Martha Judith y LARA FLORES, Sara María (coords.), Los Programas de Trabajadores Agrícolas Temporales... op.cit., pp.259-283. 
Solidarios como codesarrollo. Nosotros la resumimos como una propuesta que liga inmigración y desarrollo con el objeto que ambos países, el de origen de los inmigrantes y el de destino, se beneficien del flujo que entre ellos se establece ${ }^{27}$. En palabras de Naïr:

"la política de codesarrollo vinculada a los flujos migratorios no tiene como objetivo favorecer el "retorno" de los inmigrantes a su país de origen si no lo quieren. Al contrario, su presencia legal en Francia es precisamente la condición de la ayuda eficaz a los países de origen. Tampoco tiene como objetivo la llegada de nuevos inmigrantes, porque no predica en ningún caso la apertura general de las fronteras" 28 .

Con tal objeto conviene a esta política elaborar convenios de codesarrollo entre los países implicados para el establecimiento de proyectos en origen, principalmente de personas que regresan a sus países voluntariamente y las que se encuentran legalmente instaladas en Francia ${ }^{29}$. Este no es el caso de los trabajadores movilizados en ocasión de la contratación en origen, obligados a retornar a su país de origen y sin residencia permanente.

Sin embargo, sobre lo que pudimos observar, entre las acciones que Unió de Pagesos desarrollaba a través de su fundación durante el tiempo en el que se extendió el trabajo de campo, se encontraban la capacitación de trabajadores que manifestaban cierto interés por realizar proyectos de desarrollo en sus países de origen y la asesoría técnica en la implementación de los mismos. En atención a lo que observamos podemos comentar que las actividades de formación se reducían a un conjunto de charlas sobre lo que ellos entendían como codesarrollo y proyección de iniciativas empresariales sobre las que los trabajadores comprendían más bien poco por estar débilmente familiarizados con la implementación de proyectos, nomenclatura, etc. Sobre estas actividades Morelló indica que, a inicios del programa, se pagaba a los temporeros por participar de los cursos y existen pocos datos sobre los mismos y el modo en que éstos se financiaban ${ }^{30}$. Podríamos decir que los trabajadores escogidos para desarrollar el rol de líderes de emprendimiento local o "agentes

\footnotetext{
27 Mayor información sobre el concepto de codesarrollo y su establecimiento como modelo en España véase MORELLÓ, Núria, Entre la Oportunidad y el Deseo... op. cit.; KHOUDOUR-CASTERÁS, David, Migraciones Internacionales y Codesarrollo: Lecciones de la Experiencia Colombiana, Bogotá, Organización Internacional de las Migraciones, 2009, http://hdl.handle.net/20.500.11788/146 [Consultado el 20 de octubre de 2015]; GIMÉNEZ ROMERO, Carlos, El Codesarrollo en España: Protagonistas, Discursos y Experiencias, Los Libros de la Catarata, Madrid, 2006; CORTÉS MAISONAVE, Almudena, "Codesarrollo y Migración: una lógica transnacional. Reflexiones desde el caso español. Puntos de Vista" en Cuadernos del Observatorio de las Migraciones y de la Convivencia Intercultural de la Ciudad de Madrid, Observatorio de las Migraciones y de la Convivencia Intercultural de la ciudad de Madrid, Madrid, 2006, http://www.academia.edu/1071887/Codesarrollo_y_Migraci\%C3\%B3n_una_I\%C3\%B3gica_ transnacional._Reflexiones_desde_el_caso_espa\%C3\%B1ol [Consultado el 13 de noviembre 2016]; MALGESINI REY, Graciela, Guía Básica del Codesarrollo: Qué Es y Cómo Participar en Él, CIDEAL, Madrid, 2007; AUBARELL SOLDUGA, Gemma, OLIVÁN PENA, Helena, y ARAGALL FLAQUÉ, Xavier, "Inmigración y codesarrollo en España" en AUBARELL, Gemma (dir.), Perspectivas de la Inmigración en España: una Aproximación desde el Territorio, Icaria, Barcelona, 2003; PACHECO MEDRANO, Karina, "El codesarrollo en España: Posibilidades y desafíos" en Revista Migraciones, n 13, 2003, pp. 185-207, http://revistas.upcomillas.es/index.php/revistamigraciones/article/view/4319/4143 [Consultado el 15 de mayo de 2016]; HERRERO MUÑOZ-COBO, Blanca, Codesarrollo, alternativa para la gestión de las migraciones y desarrollo. Apuntes para la reflexión y el debate, CIDEAL, Madrid, 2000; MARCUELLO SERVós, Carmen, "Las organizaciones no gubernamentales para el desarrollo (ONGD) en España" en Revista Internacional de Sociología, n²5, 2000, pp. 99-119; y LÓPEZ, Irene y ALCALDE, Ana Rosa, Relaciones de Género y Desarrollo: hacia la Equidad de la Cooperación, Ediciones Los Libros de la Catarata, Madrid, 1999.

28 NAÏR, Sami, Informe del Balance y Orientación sobre la Política de Codesarrollo Vinculada a los Flujos Migratorios, 1997.

${ }^{29}$ Ibídem, p. 15.

${ }^{30}$ Véase MORELLÓ, Núria, Entre la Oportunidad y el Deseo... op. cit., p. 98.
} 
de codesarrollo"31, no disponían del nivel de instrucción adecuado a la formalización de los proyectos, que no se realizaban exhaustivos análisis de mercado para la implementación de los proyectos y que no se acompañaban de un refuerzo de acción en destino por parte de la fundación para mayor éxito de las empresas.

En origen y según las informaciones recabadas por otros autores, la consecución exitosa de los proyectos ha sido más bien escasa. De tal modo Kraft y De Larrard documentan la escasa rentabilidad y sostenibilidad de los proyectos implementados en Colombia: "Ios proyectos productivos en los cuales invierte el $45,9 \%$ de los temporeros son poco rentables o no sostenibles debido a la falta de acompañamiento en el momento de hacer la inversión o de capacitación en emprendimiento, y por la difícil situación económica local"32. Por otro lado Morelló advierte en su trabajo que pudo detectar

"que existía la sensación de que muchos proyectos en el pasado habían fracasado por falta de seguimientos y mantenimiento. Después de haber vivido el furor del codesarrollo, muchos de estos quedaron abandonados y sin seguimiento en origen. En el seno de esta área se evidenciaba que la interlocución en origen tenía sus fallas" ${ }^{\prime 33}$.

De igual modo advirtieron los investigadores asociados al Grupo de Investigaciones en Movilidad Humana liderado por William Mejía:

"Sin embargo, no todos los proyectos llegan a concretarse, porque no se logra el nivel de ahorros necesario o no se tiene la habilidad personal para ello, casos en los cuales todo lo ganado en España se convierte en "dinero de bolsillo", que sirve de sustento mientras se produce una nueva contratación, que a veces nunca llega, generándose dependencia respecto al programa y situaciones de inactividad laboral, porque los salarios usuales en la zona ya no se consideran aceptables o quienes ofrecen los escasos empleos prefieren otras personas "más necesitadas"'"34.

Acerca del éxito o fracaso de los proyectos emprendidos a través del codesarrollo comandado por la Fundación Agricultores Solidarios concluyen:

"De otro lado, se tuvo también información de proyectos fracasados, como en

31 Para la Fundación Pagesos Solidaris, "agente de codesarrollo" es, según su terminología, toda persona migrante que tenga una iniciativa para llevar a cabo en su comunidad de origen con la inversión de parte de sus remesas. Las iniciativas pueden ser de tipo familiar o comunitario, y los objetivos pueden ser productivos o sociales. (Notas de nuestro trabajo de campo).

32 Véase KRAFT, Robin y LARRARD, Marguerite, Codesarrollo y Migraciones Laborales Internacionales: Evaluación de los Programas de Migración Temporal y Circular entre Colombia y España. Tesis para optar al grado de Master en Economía del Desarrollo Internacional, Sciences-Po, París, 2007, pp. 119 y 120.

33 Véase MORELLÓ, Núria, Entre la Oportunidad y el Deseo... op. cit., pp. 97 y 98. En atención al trabajo de Robin Kraft y Marguerite Larrard la autora señala: "las personas contratadas en origen primero pagan sus deudas y mantienen el hogar, antes de invertir en un proyecto productivo [...] las principales inversiones productivas no son empresariales, sino de renovación o adquisición de vivienda, ( $52 \%$ de las personas temporeras), las cuales son explicadas por la obligación del retorno que conlleva el programa. También la de compra de tierra: del $13 \%$ de propietarios al iniciar la migración, un $23 \%$ tenía un terreno después de migrar (esta cifra se duplica en el caso de Nariño al ser una región profundamente campesina y pobre)". Ibídem, p. 390.

${ }^{34}$ Véase MEJÍA, William, La Experiencia del Modelo de Contratación Laboral Temporal y Circular de la Unión de Agricultores de Cataluña en Colombia, Vista desde las Comunidades de Origen de los Trabajadores, Red de Universidades Públicas del Eje Cafetero ALMA MATER, Pereira, 2008, p. 11.

https://issuu.com/ramirezgrupomovilidad/docs/alma_mater_sintesis_mltc [Consultado el 15 de junio de 2015]. 
Quindio, donde varias inversiones se dirigieron a vehículos para el transporte público, actividad en la cual los trabajadores no tenían experiencia (Mejía, 2007). Caso semejante ocurrió en Puerres con la producción de peces, donde el insuficiente conocimiento técnico condujo a la muerte de los mismos. Situación distinta, pero que refleja igualmente escasa planeación, fue la del proyecto de quinua, también en Puerres, fracasado por ausencia de mercado, evidenciada al llegar la cosecha"35.

"En el caso de Puerres, por ejemplo, lo anterior parece contribuir a explicar la existencia actual de más de cuarenta asociaciones en torno a diversos proyectos productivos, cuyo número puede llamar a engaños, si se tiene en cuenta que muchas de ellas son apenas organizaciones de papel, sin existencia real o proyectos inviable o sin sostenibilidad, creadas apenas con el propósito de satisfacer la demanda de los reclutadores" ${ }^{\prime \prime 36}$.

Podríamos establecer entonces que los trabajadores que se emplean a través del sistema de contratación de temporeros en origen de Unió de Pagesos no tienen la intención clara de ligar sus ingresos económicos ni sus remesas a proyectos de codesarrollo, sino a la inversión en proyectos privados como el pago de deudas contraídas en el pasado y el mantenimiento de la familia. De tal modo Mejía y el resto de investigadores indicaban ya en 2008:

"Es claro, entonces, que del programa se desprenden, con algunas limitaciones, beneficios económicos directos para los temporeros y sus familias, que redundan de manera inmediata en un mejor estar para el hogar durante el período del contrato y aún después de este, en función del uso que se haga de los ahorros realizados, pudiendo llegar a definir el futuro de esa familia, si logra la vinculación a varias campañas y orienta el ahorro hacia un proyecto que genere ingresos posteriores" ${ }^{\prime \prime 3}$.

\section{Conclusiones}

A través de este artículo hemos tratado de mostrar cómo la organización más importante del campo catalán ha precisado el establecimiento de todo un conjunto de programas dirigidos a la legitimación de su sistema de reclutamiento, importación, concentración y suministro de fuerza de trabajo contratada en origen. En particular hemos destacado como ha desarrollado durante la historia de su establecimiento una serie de programas de corte filantrópico asistencialista tanto en destino -es decir en el interior de los alojamientos que se disponen como habitación para los trabajadores, en los distintos municipios agrícolas donde éstos se encuentran y más allá en parte del territorio catalán en el que se desarrollaron diversas actividades ligadas al ocio obrero- como en origen a través de la puesta en marcha de programas de codesarrollo que originaron diversos proyectos.

Su descripción sirve a efectos de desvelar el objetivo implícito de la organización por

\footnotetext{
35 Ibídem, p. 12.

${ }^{36}$ Ibíd., p. 18.

${ }^{37}$ Ibíd., p. 12.
} 
garantizar la legitimación social de un sistema cuyos efectos caracterizamos de perversos atendiendo la limitación de los derechos fundamentales de los trabajadores que el mismo provoca. Tal objetivo Resulta congruente, no obstante, con el modelo disciplinario que se intenta aplicar a la mano de obra a través de su establecimiento y cuyo principal resorte se encuentra en el espacio destinado a la concentración -normativa de alojamiento, régimen interno de vida, sometimiento a vigilancia por personal encargado-. Un modelo disciplinario que se precisa para el correcto funcionamiento del sistema por el que se prevé el suministro de la fuerza de trabajo justo en el momento en que se precisa en el lugar idóneo. La finalización exitosa de la campaña agrícola y el desarrollo de los diversos enclaves agrícolas catalanes en condiciones de competencia en los mercados internacionales, son los objetivos principales de su instalación. Acorde con estos intereses del empresariado, se encuentran aquellos del Estado representados en el control de los flujos en atención a las necesidades específicas de mano de obra en la agricultura intensiva catalana.

La presentación de tal sistema precisó en sus orígenes un proyecto en paralelo destinado a mitigar las críticas que a inicios de su establecimiento se produjeron por parte de grupos de estudiantes de ideología marxista, comunista y anarquista; como por trabajadores extranjeros, en su mayor parte en situación jurídica irregular, que veían en el mismo una expropiación de su principal modo de subsistencia y la privación de acceso a uno de los pocos nichos laborales en los que se permitía su presencia: la agricultura.

Según nuestro criterio y forma de interpretar los hechos de los que hemos sido observadores, tanto los cursos que se intentaban dar como el ocio administrado a través de comidas de hermandad o excursiones, no han servido sino a la publicidad de una suerte de patrocinio, de lo que Unió de Pagesos y la Fundación Agricultores Solidarios han acordado en representar como inmigrantes desposeídos. De tal forma, desarrollaron proyectos de gestión de grupos humanos cuyo principal interés por participar de ellos no era sino la obtención de trabajo en España.

En lo que al establecimiento de proyectos de codesarrollo refiere no podemos sino convenir que se ha tratado de un programa que sirve asimismo al objetivo de legitimación del sistema de contratación de temporeros. En el caso colombiano han sido diversos trabajos los que han tratado de mostrar la poca efectividad del modelo en cuanto a sus niveles de éxito. Amén de esto surge la cuestión relativa a la consideración del programa de codesarrollo implementado en ocasión de este sistema de contratación en origen como codesarrollo, esto en atención a la obligación de retorno de los trabajadores importados. En condiciones de permanencia de los trabajadores en situación legal en los países de destino, parece más apropiado denominar como codesarrollo a aquellos programas que se realizan en ocasión de envío de remesas a las familias que residen en los países de origen. No obstante, teniendo en cuenta la excepcional situación jurídica de los trabajadores contratados mediante el sistema de Unió de Pagesos, limitados en sus libertades de circulación, trabajo y domicilio, entre otros, no nos parece apropiada la consideración de codesarrollo, al menos en atención a lo que convino sobre el mismo su principal teórico Sami Naïr.

Concluyendo que de lo que se trata es de la movilización de unfree labor en términos de Décosse, nos parece descabellado, y aún nefasto, la calificación de codesarrollo a programas 
que se establecen en ocasión del uso de remesas de trabajadores en situación jurídica de servidumbre. El fracaso de los mismos ha venido a ser consignado por varios autores y gracias a sus trabajos hemos podido comprobar, como en el caso de Morelló en Colombia, cómo toda vez se implementan estos proyectos en origen reverdecen las estructuras clientelares que guían parte de los comportamientos de estas sociedades reproduciendo su jerarquía.

\section{Bibliografía}

ABELLA, Manolo, "Policies and best practices for management of temporary migration", Ponencia Presentada en el International Symposium on International Migration and Development, Secretaría de las Naciones Unidas, Turín, 2006.

ACHÓn RODRÍGUEZ, Olga, Importando Miseria. La Alternativa a la Provisión de Mano de Obra Agrícola, Los libros de la Catarata, Madrid, 2011.

ACHÓN RODRÍGUEZ, Olga, "Alojamientos para trabajadores agrícolas extranjeros contratados en origen y privación de libertades. El caso del sistema de alojamiento propuesto por el sindicato agrícola Unió de Pagesos en la comarca del Segriá (Lleida)" en FERNÁNDEZ AVILÉS, José Antonio y MORENO VIDA, María Nieves, (dirs.), Inmigración y Crisis Económica: Retos Políticos y de Ordenación Jurídica, Ed. Comares, Granada, 2011, pp. 533-546.

ACHÓN RODRÍGUEZ, Olga, "Hacia la comunitarización de las relaciones laborales en España. El sistema de reclutamiento y suministro de trabajadores extranjeros en origen del sindicato agrícola Unió de Pagesos" en La Razón Histórica. Revista de Historia de las Ideas, n¹5, 2011, pp. 20-39.

ACHÓN RODRIGUEZ, Olga, "Contratación de temporeros por la Unió de Pagesos: un sistema sorprendente y censurable" en Revista Aranzadi Social, n4, 2011, pp. 201-231.

ACHÓN RODRÍGUEZ, Olga, "Colombianos para la fruticultura leridana. Análisis crítico de los protocolos de reclutamiento de temporeros" en SÁNCHEZ GÓMEZ, Martha Judith y LARA FLORES, Sara María (coords.), Los Programas de Trabajadores Agrícolas Temporales. ¿Una Solución a los Retos de las Migraciones en la Globalización?, Universidad Nacional Autónoma de México e Instituto de Investigaciones Sociales, México, 2015, pp. 285-318.

AUBARELL SOLDUGA, Gemma, OLIVÁN PENA, Helena, y ARAGALL FLAQUÉ, Xavier, "Inmigración y codesarrollo en España" en AUBARELL, Gemma (dir.), Perspectivas de la Inmigración en España: una Aproximación desde el Territorio, Icaria, Barcelona, 2003.

AUGÉ, Marc, Los "no lugares". Espacios del Anonimato. Una Antropología de la Sobremodernidad, Gedisa, Barcelona, 2000.

BASOK, Tanya, BÉLANGER, Danièle, CANDIZ, Guillermo y RIVAS, Eloy, "Espacios de "ilegalidad": el caso de trabajadores mexicanos en dos comunidades rurales de Canadá" en SÁNCHEZ GÓMEZ, Martha Judith y LARA FLORES, Sara María (coords.), Los Programas de Trabajadores Agrícolas Temporales. ¿Una Solución a los retos de las Migraciones en la Globalización?, Universidad Nacional Autónoma de México e Instituto de Investigaciones Sociales, México, 2015, pp. 25-53.

CORTÉS MAISONAVE, Almudena, "Codesarrollo y Migración: una lógica transnacional. Reflexiones desde el caso español. Puntos de Vista", Cuadernos del Observatorio de las Migraciones y de la Convivencia Intercultural de la ciudad de Madrid, Observatorio de las Migraciones y de la Convivencia Intercultural de la ciudad de Madrid, Madrid, 2006.

DE GAUDEMAR, Jean Paul, La Movilización General, La Piqueta, Madrid, 1981.

DÉCOSSE, Frédéric, "Migración circular, (in)movilidad laboral y unfree labour. Una reflexión a partir del caso de los contratos OMI en Francia" en SÁNCHEZ GÓMEZ, Martha Judith y LARA FLORES, Sara María (coords.), Los programas de trabajadores agrícolas temporales. ¿Una solución a los retos de las migraciones en la globalización?, Universidad Nacional Autónoma de México e Instituto de Investigaciones Sociales, México, 2015, pp. 259-283.

FOUCAULT, Michel, Saber y Verdad. Madrid, Las Ediciones de La Piqueta, Madrid, 1991.

FOUCAULT, Michel, La Verdad y las Formas Jurídicas, Gedisa, Barcelona, 1973.

FOUCAULT, Michel, Historia de la Locura en la Época Clásica, Fondo de Cultura Económica, Barcelona, 1990.

FOURQUET, François y MURARD, Lion, Los Equipamientos del Poder. Ciudades, Territorios y Equipamientos Colectivos, Editorial Gustavo Gili, Barcelona, 1978.

GIMÉNEZ ROMERO, Carlos, El Codesarrollo en España: Protagonistas, Discursos y Experiencias, Ediciones Los Libros de la Catarata, Madrid, 2006.

GOFFMAN, Erving, Internados. Ensayos sobre la Situación Social de los Enfermos Mentales, Amorrortu, Buenos Aires, 2001.

HERRERO MUÑóZ-COBO, Blanca, Codesarrollo, Alternativa para la Gestión de las Migraciones y 
Desarrollo. Apuntes para la Reflexión y el Debate, CIDEAL, Madrid, 2000.

IZCARA PALACIOS, Simón Pedro, "Irregularidades en el reclutamiento de trabajadores agrícolas con visas H-2A en México" en SÁNCHEZ GÓMEZ, Martha Judith y LARA FLORES, Sara María (coords.), Los Programas de Trabajadores Agrícolas Temporales. ¿Una Solución a los Retos de las Migraciones en la Globalización?, Universidad Nacional Autónoma de México e Instituto de Investigaciones Sociales, México, 2015, pp. 207-233.

KHOUDOUR-CASTERÁS, David, Migraciones Internacionales y Codesarrollo: lecciones de la experiencia colombiana. Bogotá, Organización Internacional de las Migraciones, 2009.

KRAFT, Robin, y LARRARD, Marguerite, Codesarrollo y Migraciones Laborales Internacionales: Evaluación de los Programas de Migración Temporal y Circular entre Colombia y España. Tesis para optar al grado de Master en Economía del Desarrollo Internacional, Sciences-Po, París, 2007.

LÓPEZ, Irene y ALCALDE, Ana Rosa, Relaciones de Género y Desarrollo: hacia la Equidad de la Cooperación, Ediciones Los Libros de la Catarata, Madrid, 1999.

LÓPEZ-SALA, Ana y GODENAU, Dirk, "En torno a la circularidad migratoria: aproximaciones conceptuales, dimensiones teóricas y práctica política" en Migraciones, n 38, 2015.

MALGESINI REY, Graciela, Guía Básica del Codesarrollo: Qué Es y Cómo Participar en Él, CIDEAL, Madrid, 2007.

MARCUELLO SERVÓS, Carmen, "Las organizaciones no gubernamentales para el desarrollo (ONGD) en España" en Revista Internacional de Sociología, n²5, 2000, pp. 99-119.

MARTIN, Philip, Managing Labor Migration: Temporary Worker Programs for the 21st Century, Internacional Institute for Labour Studies/OIT, Ginebra, 2003.

MATA-CODESAL, Diana, Circular Codevelopement. Codevelopement for Temporary Migration Programs, 2007.

MEJÍA, William, (coord.) La Experiencia del Modelo de Contratación Laboral Temporal y Circular de la Unión de Agricultores de Cataluña en Colombia, Vista desde las Comunidades de Origen de los Trabajadores, Red de Universidades Públicas del Eje Cafetero ALMA MATER, Pereira, 2008.

MILLÁN JALDÓN, Juan Antonio, "Modelo Cartaya de Migración Circular: su definición conceptual y estratégica. Fórmula de codesarrollo idónea para fomentar flujos migratorios legales, complementar el control de frontera y la lucha contra el tráfico ilegal de personas y la migración ilegal" en GORDO MÁRQUEZ, Mercedes y FELICIDADES GARCÍA, Jesús (eds), Explorando los Contratos en Origen en los Campos Españoles, Universidad de Huelva, Huelva, 2009, pp. 147154.

MORELLÓ, Núria, Entre la Oportunidad y el Deseo. Contratación en Origen, Codesarrollo y Grupos Domésticos Transnacionales en el Mundo Rural. El Caso Catalunya-Colombia, Tesis inédita, 2016.

MOULIER-BOUTANG, Yann, De la Esclavitud al Trabajo Asalariado. Economía Histórica del Trabajo Asalariado Embridado, Akal, Madrid, 2006.

MUIR, Gwendolyn, "Descifrar los espacios de exclusión. El control de la migración y el reclutamiento de trabajadores guatemaltecos en Canadá a través del programa de trabajadores temporales extranjeros" en SÁNCHEZ GÓMEZ, Martha Judith y LARA FLORES, Sara María (coords.), Los Programas de Trabajadores Agrícolas Temporales. ¿Una Solución a los Retos de las Migraciones en la Globalización?, Universidad Nacional Autónoma de México e Instituto de Investigaciones Sociales, México, 2015, pp. 57-80.

NAÏR, Sami, Informe del Balance y Orientación sobre la Política de Codesarrollo Vinculada a los Flujos Migratorios, 1997.

PACHECO MEDRANO, Karina, "El codesarrollo en España: Posibilidades y desafíos" en Revista Migraciones, $\mathrm{n}^{\circ} 13,2003$, pp. 185-207.

RUHS, Martin, Temporary Foreign Workers Programs: Policies, Adverse Consequences and the Need to Make them Work, CCIS/University of California, San Diego, Documento de trabajo, n6/2002.

SIERRA ÁLVAREZ, José, El Obrero Soñado. Ensayo sobre el Paternalismo Industrial (Asturias, 18601917), Siglo XXI, Madrid, 1990.

TRIGUEROS LEGARRETA, Paz "La contratación de trabajadores agrícolas con visas H-2A. Del Programa Bracero a la situación actual" en SÁNCHEZ GÓMEZ, Martha Judith y LARA FLORES, Sara María (coords.), Los Programas de Trabajadores Agrícolas Temporales. ¿Una Solución a los Retos de las Migraciones en la Globalización?, Universidad Nacional Autónoma de México e Instituto de Investigaciones Sociales, México, 2015, pp. 173-206.

ZAPATA-BARRERO, Ricard, FAÚNDEZ, Rocío y SÁNCHEZ-MONTIJANO, Elena, Migración Laboral, Temporal y Circular (MLTC) de Trabajadores entre Colombia y España. Un Modelo a Consolidar y Replicar, 2009. 